\title{
Entering the Russian Market: The Peculiarities for Foreign Companies
}

\author{
N.I. Ivanova ${ }^{1, *}$ \\ *Corresponding author: cleotasha@ rambler.ru \\ ${ }^{1}$ Samara State University of Economics, Samara, Russia
}

\begin{abstract}
Entering a foreign market is always a challenge. This is especially true under the economic, political and cultural changes that are constantly taking place. Revealing the target markets' peculiarities is the initial phase of any entry and promotion strategy. The market of the largest country in the world - the Russian market - is of the greatest interest today. Its special traits descriptively summarized and examined in the paper may give a foreign company an advantage entering the market. The promotion strategies that to some extend meet the peculiarities of the Russian business environment promise to be more effective on the Russian market.
\end{abstract}

Keywords: business environment, entry and promotion strategies, cultural differences, marketing strategies, cultural convergence.

\section{Introduction}

The marketing environment with all its specific aspects is a key for the success of a company on a new market. The political and economic environment keeps changing in any country thus impeding market entrance for foreign companies. Certain marketing procedures - a thorough analysis at least - are surely needed to reduce the risks when entering the market.

Russian market remains a puzzle for foreign companies. This hinders foreign trade and business cooperation though cultural peculiarities are typical for any country (take Asian countries to get a vivid example). Even business cultures these that are considered to be formal and universal - do differ in different countries. Developing and implementing a proper promotion strategy that meets the cultural peculiarities of a certain country is a true challenge even for a global mature company.

\section{Problem Statement}

The Russian market remains an arguable issue in scientific literature. Its cultural peculiarities are of great interest. The paper intends to bridge the remaining gap.

The promotion strategies that to some extend meet the peculiarities of the Russian business environment promise to be more effective on the Russian market. Thus these peculiarities need to be revealed, summarized and at least described.

Further research on the topic may as well be quantitative as it seems perspective to hypothesize the more and less crucial characteristics of the Russian market, and test the hypotheses statistically (using a specially designed interview, for instance, with both foreign and domestic companies participating).

\section{Research Questions}

"Does the national culture component really matter when entering the Russian market?" is the basic research question. "What is so specific about the Russian market?" and "What traits are surely to be considered by foreign companies?" are the sub-questions.

\section{Purpose of the Study}

In this paper we aim to summarize, describe and explain the basic traits of the Russian market. The key objective is to reveal the role of the national culture component in promoting a product with the special attention paid to the case of the Russian market. 


\section{Research Methods}

The qualitative approach is dominant in the paper with special attention paid to the analysis of texts, documents and relevant data. The latter are used to induce the arguments and explanations.

The research philosophy is interpretivism. The research design is descriptive seeking the main aim to describe and examine the factors having a particular place and time.

Descriptive research implies a researcher that does not have any control over the variable and helps clarifying and describing a problem more completely via data collecting.

Revealing the traits of the Russian market is a non-quantified matter, thus the descriptive research method seems to the most effective. In this paper we do not intend to test, measure and verify the market's features statistically.

\section{Findings}

Marketing environment is regarded as a tool that assesses the ability of a company to enter a foreign market and interact with consumers. It embraces "the actors and forces outside marketing that affect marketing management's ability to build and maintain successful relationships with target customers" [1].

This environment is constantly changing. If a company plans to be successfully present worldwide, then these changes are to be monitored, foreseen (as far as it is possible) and considered. The changes may be either rapid or gradual. In case of gradual shifts companies at least have time to modify the marketing strategies. Legislation evidently has a serious impact on business by implementing rules, bans and sanctions.

Consumerism is another ingredient of a company's environment that influences its success whether entering a new market or promoting a new product. Consumerism implies two quite different approaches. The first one admits customers' dominance: it's the customer who decides a product's or company's fate on the market. The second one, on the contrary, denies any significance of customers: they just consume having no influence on what products are produced [2].

The more a customer is informed on the product, the more dominance he has. Consequently scarce information leads to control over a customer. A company seeking for power over a customer is to maintain a subtle balance: if a consumer is not informed on a product's features in detail, then he is less willing to purchase it. Moreover, if a producer starts cheating its customers exploiting their ignorance, then this causes serious reputation damages, the producer's negative image and financial losses [3].

Even global companies are still stick to the concept of cultural convergence denying the national, ethic, cultural and religious differences among markets. The concept implies very similar buying behavior in different countries: consumers' needs are almost identical on any market and so are the ways to satisfy them. So companies address different markets with the same product ignoring the cultural aspects of each particular country [4].

But the cultural convergence concept does not fit absolutely all companies. Thus if a producer plans to launch a product on numerous foreign markets, then it is to develop a neutral promotion campaign that will definitely not insult any existing religion or national tradition. The Coca-Cola beverages, for instance, are present on the market of almost every country in the world, and the company does not directly appeal to any religion or national tradition. But it does consider certain cultural aspects during the launching and promoting period: uniquely designed ads appear in different countries trying to communicate with potential customers at a more close and personal level. This is localized promotion on the global market.

Each country obviously has very particular socio-cultural features. These influence launching and promoting strategies and consequent marketing decisions. The three socio-cultural forces are admitted today:

$\checkmark$ the demographic profile of a country,

$\checkmark$ the cultural differences within and between nations,

$\checkmark$ the impact of consumerism [5].

Launching and promoting strategies are highly dependent on a country's demographic profile. If the elderly outnumber the newborns, then promoting strategies are to be adjusted:

a) companies targeting the segment for the newborns must reverse the decision to enter the country's market,

b) companies should shift to the segment for the elderly and focus on the products specifically designed for the elderly age groups [6].

Culture in every country today is tending to get modified as it is heavily influenced by other (primarily western) cultures and new (again primarily western) living standards. Thus companies are to consider the new cultural trends to benefit from the emerging target audiences. Demographic shifts and changes in social attitudes are of crucial importance for the launching and promoting procedures. The Russian consumer market is very different from any other market. This is for the following revealed reasons.

Firstly, the economic stagnation after the collapse of the Soviet Union influenced greatly the business culture, market and all the aspects liked to business relations. Domestic companies got instantly (with no transition period) exposed to virtually unknown marketing tools like product promotion, advertising campaigns and market segmentation [7]. Foreign companies similarly found it difficult to get adopted to the situation on the new post-Soviet market [8]. 
Secondly, the Russian market continues to be non-sustainable staggered by the global economic crisis of 2008 and the recession that followed. Thus foreign producers may have been affected negatively. Domestic companies may have benefited from devaluation of the Russian national currency and import substituting initiatives.

Thirdly, Russian market is becoming more and more attractive especially for manufacturers from the countries of BRICS [7] as the purchasing power of Russian consumers has grown substantially since the financial crisis of 1998 .

Fourthly, Russian market attracts foreign producers as the income tax stays at rather a low level, energy is cheap and living costs are not as high as in western countries.

Finally, Russians tend to spend rather than to save. This creates a favorable environment for the industries that produce consumer goods.

Business cultures are quite different in various countries. The business culture in Russia is to some extend typical [9] but does have unique features. These are to be considered if a company has ambitions on the Russian market and is looking for secure business relationships.

A simple hierarchy model within an organization, a very high index of power distance and paternalism are among the specific traits of Russian business culture [10]. It's not typical for Russian businessmen to work or negotiate under pressure in a rush atmosphere. A too persistent negotiator may even be considered rude and unprofessional by a Russian counterpart. Russians respect punctuality and are always eager for details as they tend to understand a topic fully and deeply. If a Russian likes a business idea, he will try to implement it as soon as possible. A European counterpart, on the contrary, will prefer to think it over thoroughly and weigh all the pros and cons. Russians may tend to act quickly and from a position of strength. They may neither look for a compromise nor try to reach an agreement beneficial for all [11].

Entering a foreign market is a challenge for any company especially small and medium sized. Even choosing an entry mode is a complex controversial process with a myriad of alternatives [12]. Exploiting the opportunities of a new market as effectively as possible becomes an even more serious problem.

The entrance strategies may differ and depend upon such factors as

a) the current economic and political situation in the target country,

b) business-environment,

c) the external and internal forces influencing the company.

The internal ones may imply the technologies used and the level of economic efficiency being achieved by the time of entering the new market.

The strategy choice is also determined by the type of business a company is planning to get involved in Russia. Thus it will prefer either a representative office or a joint venture or an acquisition or even a greenfield investment.

The following are the crucially important factors for foreign companies entering Russian market:

1) the strategy (the time, location and type of operation) - it is to be carefully planned beforehand as strategic decisions are rigid and can hardly be reversed after [13];

2) HR and employment details - these are softer than the previous ones and can be modified both in the course of the entering process and after it;

3) adequate marketing tools;

4) face-to-face negotiations and frequent business trips to Russia are recommended.

The strategy as well implies the identification of the boom-and-bust cycle phase [6] of the Russian economy. It's a dead-end to try entering the Russian market whilst the economy is in recession: unemployment surges, consumers' purchasing ability declines and even domestic companies go bankrupt. However, all the above is true for any country.

A SWOT analysis is rather an effective instrument applicable to the economy of Russia. It may help to reduce uncertainty.

PEST factors (political, economic, socio-cultural, technological) are to be considered. These may as well be SWOTanalyzed.

A SWOT analysis may be improved by:

$\checkmark$ tracking the major trends of the business environment;

$\checkmark$ revealing the impact of each trend on the target market, the company and product;

$\checkmark$ extrapolating the trends into the future thus to forecast their development and further impact [14].

There are numerous foreign companies operating in Russia today. American companies have started entering the Russian market before 2000. The first one to start business in the Soviet Union was PepsiCo. Forty years of its operation on the market have resulted in 30,000 jobs and more than 3 billion US dollars of investments. US companies are still considered to have a more promising view of the Russian market than do their European counterparts [15].

Hempel - a top Danish coatings supplier for industrial and decorative purposes - entered the Russian market in 2015. The factory is located in Ulyanovsk with its convenient infrastructure and the geographical position that optimizes deliveries to Russian and European customers. AkzoNobel from the Netherlands and Tikkurila from Finland are successfully operating in Russia.

The list is surely not exhaustive. On the whole, food and beverage, chemical and manufacturing industries are the sectors that are the most attractive for foreign companies.

Foreign companies agree that the best way to promote a product in Russia is through TV advertising, B2B offers and internet advertising. This reflects the rapid changes on the entertainment market in Russia. 


\section{Conclusion}

Below we shall summarize the main results achieved.

A successful entry strategy is to consider the issues:

$\checkmark \quad$ nothing is to be associated with religion and racism. Consumers find it unethical and abusing;

$\checkmark \quad$ stereotypes existing in a particular country may to be exploited;

$\checkmark$ consumers are more likely to be aware of the cultural aspects, so the promotion campaign that appeals to certain cultural peculiarities is definitely more preferable than a neutral one;

$\checkmark \quad$ economic and political environment is to be carefully monitored;

$\checkmark \quad$ a cross-cultural intermediary responsible for conducting negotiations will be helpful.

The above universal issues are applicable for the case of Russia. But we surely need to complement them:

$\checkmark \quad$ advertising a product in Russia must not involve any politics or politicians. Otherwise the advertising campaign is doomed to failure;

$\checkmark \quad$ the luxury segment has always been rather stable on the Russian market despite economic recessions;

$\checkmark$ however, Russian consumers tend to buy low-cost products. A company seeking for success on the Russian market should as well target this audience;

$\checkmark \quad$ Russian customers are sensitive to cultural aspects. Thus any advertising campaign is to consider this fact;

$\checkmark \quad$ political and economic environments in Russia are volatile. All the shades of political (legislative) and economic processes are to be monitored and to the possible extend forecast. Special attention is to be paid to the ruble exchange rate (particularly if a company imports the components);

$\checkmark \quad$ companies are not likely to face HR problems as the labor-force in Russia is qualified enough to fill practically any position within a foreign enterprise;

$\checkmark \quad$ Russians go patiently into the details of a business project. Once they get confident in its success, they will start implementing the project almost immediately. Foreign negotiators are to be prepared for such a peculiarity and be ready to answer numerous questions of the Russian counterpart and to launch the project just on exiting the office.

Russian market does not promise quick profits. It's a long-time challenge to win success on the market of the largest country in the world.

\section{References}

1. P. Kotler, G.Armstrong, Principles of marketing. 17th ed. Pearson: Global Edition (2017).

2. R.H. Buskirk, J.T. Rothe, Consumerism - an interpretation. Journal of Marketing, 34(4), 61-65. DOI: 10.2307/1250713 (1970).

3. R.S.N. Pillai, V. Bagavathi, Marketing management. New Delhi, India: S. Chand Publishing (2012).

4. A. Palmer, Principles of marketing. Oxford: Oxford University Press (2000).

5. D. Jobber, F. Ellis-Chadwick, Principles and practice of marketing. 8th ed. London: Mc Graw Hill Education (2016)

6. J. Blythe, Essentials of marketing. 3rd ed. Harlow: Pearson Education Limited (2005).

7. I. Wilson, M. Mukhina, Market segmentation in Russian subsidiaries of FMCG MNEs: Practitioner and academic perspectives. Marketing Intelligence and Planning, 30(1), 53-68. DOI: 10.1108/02634501211193912 (2012).

8. G.R. Fallon, A. Jones, Marketing in Russia by UK businesses: Lessons from a survey of trade missioners to Moscow. Journal of Small Business and Enterprise Development, 11(2), 174-185. DOI: 10.1108/14626000410537119 (2004).

9. P. Gerendasi, Doing business and investing in the Russian Federation. Moscow: PricewaterhouseCoopers Russia. Retrieved from: https://www.pwc.ru/en/doing-business-in-russia/assets/doing-business-russian-federation-2010.pdf (2010).

10. G. Balykina, Intercultural aspect of Russian business negotiation practices. SSRN Electronic Journal. January. DOI: 10.2139/ssrn.2577188 (2015).

11.J. Ketting, Doing business in Russia. Do's and don'ts and success factors in Russia. Lighthouse Russia BV. Retrieved

from: http://www.thelighthousegroup.ru/client/lighthouse/uploads/presentations/presentation_hiswa_trade_mission_april_ 2009.pdf (2009).

12. S. Hollensen, Global marketing: A decision-oriented approach. 5th ed. Harlow: Pearson Education Limited (2011).

13. M. Schorsch, Market entry strategies for Russia. A comprehensive survey based on expert interviews. Hamburg: Diplomica Verlag GmbH (2009).

14. L. Moutinho, C.S. Chien, Problems in marketing. Applying key concepts and techniques. 2nd ed. London: Sage Publications Ltd. DOI: 10.4135/9781446220948 (2008).

15. G. Irwin, T. Gratowski, A. Smotrov, Multinationals in Russia in 2015. Moscow: Global Counsel. Retrieved from: https://www.global-counsel.co.uk/sites/default/files/specialreports/downloads/Global_Counsel_Multinationals_in_Russia_in-2015.pdf (2015). 